\title{
ANALISIS KEPUASAN PELANGGAN DENGAN METODE SERVQUAL DI RUMAH SAKIT CONDONG CATUR YOGYAKARTA
}

\author{
Octaviana Mardikanto $^{1}$, Eddy Kristiyono ${ }^{2}$, Farisya Nurhaeni ${ }^{3}$ \\ 1,2,3 POLTEKES BSI Yogyakarta \\ aviokto@gmail.com
}

\begin{abstract}
The purpose of this study was to measure customer satisfaction through the analysis of gaps that occur between the customer and the provider based on the dimensions of service quality with SERVQUAL method. This type of research is descriptive method of Cross Sectional Survey. The subjects were managers (9), front-line employees (100 people) and patients (200 people) in RS Condong Catur Yogyakarta. Samples for managers and front-line employees are the entire population, the patient sample is probabilistic sampling (proportionate sampling). The research instrument is a questionnaire with a seven-point scale. The results show customer satisfaction in the RSCC is still low in the presence of a negative value. Gap Calculation not weighted 5 resulted in a score of -1.05 , and a weighted score of -0.21 , with the largest gap in the dimensions of Reliability (-0.23). This indicates that the patient's expectations is greater than reality, then the quality of services received is not satisfactory and there arose a patient dissatisfaction. The conclusions of this research is in the RSCC patient satisfaction overall remains low in the presence of a negative value.
\end{abstract}

Keywords: satisfaction, servqual

\begin{abstract}
Abstrak
Tujuan penelitian ini adalah mengukur kepuasan pelanggan melalui analisis kesenjangan yang terjadi antara customer dan provider berdasarkan dimensi kualitas jasa dengan metode Servqual. Jenis penelitian ini adalah deskriptif dengan metode Cross Sectional Survey. Subyek penelitian terdiri manajer (9 orang), karyawan lini depan (100 orang) dan pasien (200 orang) di RS Condong Catur Yogyakarta. Sampel untuk manajer dan karyawan lini depan adalah seluruh populasi, sampel pasien adalah probabilistic sampling (proportionate sampling). Instrumen penelitian ini adalah kuesioner dengan seven-point scale. Hasil penelitian menunjukkan kepuasan pelanggan di RSCC masih rendah dengan adanya nilai yang negatif. Penghitungan Gap 5 menghasilkan skor tidak tertimbang sebesar $-1,05$, dan skor tertimbang sebesar $-0,21$, dengan gap terbesar pada dimensi Reliability $(-0,23)$. Hal ini menunjukkan bahwa harapan pasien lebih besar daripada kenyataan, maka kualitas jasa yang diterima tidak memuaskan dan timbullah ketidakpuasan pasien. Simpulan penelitian ini adalah kepuasan pasien di RSCC secara keseluruhan masih rendah dengan adanya nilai yang negatif.
\end{abstract}

Kata kunci: kepuasan, servqual

\section{PENDAHULUAN}

Industri jasa memainkan suatu peranan penting dalam perekonomian dalam banyak negara. Dalam kompetisi lingkungan global saat ini penyampaian pelayanan yang berkualitas sangat dipertimbangkan sebagai suatu strategi esensial untuk mencapai keberhasilan dan ketahanan. Dikarenakan penyampaian pelayanan terjadi saat interaksi antara karyawan kontak dan pelanggan, maka perilaku dan sikap para karyawan kontak dapat mempengaruhi persepsi pelanggan tentang kualitas jasa. Kualitas jasa yang dirasakan dihasilkan dari perbandingan antara harapan dengan persepsi mereka tentang jasa yang disampaikan oleh penjual. Jika harapan lebih tinggi daripada kenyataannya, maka kualitas yang dirasakan kurang memuaskan dan pasti menimbulkan ketidakpuasan pelanggan. ${ }^{1}$

Kualitas merupakan satu dari banyak hal yang diharapkan pelanggan produk jasa. Kualitas jasa dapat didefinisikan secara luas sebagai proses pertemuan harapan pelanggan atau penyediaan pelayanan sempurna. Dapat juga didefinisikan sebagai kemampuan suatu instansi untuk memenuhi bahkan melampaui harapan pelanggan. ${ }^{2}$ Pelayanan jasa kesehatan berbeda dengan pelayanan sektor jasa lain. Kualitas jasa dalam perawatan pasien berkaitan 
dengan penyampaian dalam pelayanan perawatan pasien. ${ }^{3}$ Dalam pelayanan kesehatan, diperlukan pelayanan yang berkualitas demi mendukung jalannya upaya penyembuhan pasien. Sebagaimana Bitner dkk mengungkapkan bahwa interaksi antara pelanggan dan penjual adalah saat sesungguhnya terjadi interaksi antara penjual dan pembeli, dan saat itulah terjadi produksi pelayanan ( Kaltcheva \&Parasuraman, 2009).

Literatur manajemen menuliskan banyak konsep dan pendekatan yang memikirkan tentang bagaimana menciptakan kualitas jasa, dan juga banyak konsep yang berbeda tentang bagaimana memahami tentang kualitas jasa. Salah satu teori yang mempelajari tentang service quality adalah teori Servqual. Menurut Parasuraman et al (1990) kualitas jasa dapat didefinisikan sebagai suatu penilaian keseluruhan yang serupa dengan perilaku saat pelayanan dan secara umum diterima sebagai suatu anteseden dari kepuasan pelanggan keseluruhan. Beliau

juga mendefinisikan kualitas jasa sebagai kemampuan suatu organisasi dalam memenuhi atau melampaui harapan pelanggan. Inilah perbedaan antara harapan pelanggan dan jasa yang dirasakan (Tjiptono,2006).

Dalam menilai kualitas jasa model Servqual ini pelanggan mengevaluasi lima dimensi, yaitu Reliability, Responsiveness, Assurance, Empathy, dan Tangibles melalui gap yang terjadi antara jasa yang diharapkan dan jasa yang dirasakan oleh pelanggan (Service Gap). Analisis ini bertujuan untuk mengukur tingkat kepuasan pelanggan di RSCC dengan metode Servqual.

\section{METODE PENELITIAN}

Penelitian ini adalah menggunakan rancangan penelitian Cross Sectional Survey. Penelitian dilakukan di RS Condong Catur Yogyakarta, dengan periode waktu penelitian dari bulan Oktober sampai dengan Desember 2011. Kriteria inklusi responden pelanggan adalah (1) Semua pasien rawat jalan, (2) Pasien dewasa dengan kondisi kesadaran penuh, (3) Pasien anak, yang saat survei diwakili oleh orangtuanya, (4) Pasien yang membayar jasa pelayanan rawat jalan dan inap, baik membayar sendiri maupun melalui asuransi, (5) Pasien rawat inap yang telah dirawat minimal $48 \mathrm{jam}$. Sampel pelanggan yang diambil terdiri dari pasien rawat inap dan rawat jalan sebanyak 200 responden. Cara pengambilan sampel untuk pelanggan dengan teknik non probabilistic sampling, yaitu purposif sampling dari angka kunjungan rawat inap dan kunjungan rawat jalan (UGD, dan Unit Rawat Jalan). Survei menggunakan kuesioner model Servqual dengan 22 item untuk menilai ekspektasi dan persepsi pelanggan melalui lima dimensi kualitas (Tangibles, Reliability, Responsiveness, Assurance, Empathy), dengan menggunakan seven-point scale. ${ }^{5}$ Data yang telah diperoleh dari kuesioner tadi, kemudian dibuat ratarata skor dan dihitung sesuai tahapan penghitungan gap 5.

\section{HASIL}

Hasil penelitian menunjukkan bahwa secara keseluruhan kepuasan pasien di RSCC dinilai rendah, dengan adanya nilai yang negatif. Semakin negatif skor Servqual maka gap yang terjadi di mata pasien semakin serius. ${ }^{6}$ Hasil pengukuran kepuasan secara keseluruhan digambarkan pada Gap 5, yang mempunyai skor negatif $(-1,05)$ dengan rincian skor terdapat pada tabel 1 berikut :

Tabel 1. Kesenjangan antara Jasa yang diharapkan dan Jasa yang dirasakan/dipersepsikan oleh pasien (Gap 5), Skor Tidak Tertimbang/ Unweighted

\begin{tabular}{llll}
\hline Faktor kepuasan & $\begin{array}{l}\text { Jasa yang } \\
\text { diharapkan } \\
\text { pasien } \\
\text { (a) }\end{array}$ & $\begin{array}{l}\text { Jasa yang } \\
\text { dirasakan } \\
\text { pasien } \\
\text { (b) }\end{array}$ & $\begin{array}{l}\text { Gap 5 } \\
\text { (b-a) }\end{array}$ \\
\hline $\begin{array}{l}\text { Gap 5 } \\
\text { (Unweighted Score) }\end{array}$ & $\mathbf{6 , 3 3}$ & $\mathbf{5 , 2 8}$ & $\mathbf{- 1 , 0 5}$ \\
Tangibles & 6,16 & 5,13 & $-1,03$ \\
Reliability & 6,47 & 5,34 & $-1,13$ \\
Responsiveness & 6,37 & 5,41 & $-0,95$ \\
Assurance & 6,32 & 5,38 & $-0,94$ \\
Empathy & 6,33 & 5,17 & $-1,16$ \\
\hline
\end{tabular}

Tabel 1 menunjukkan skor Gap 5 tidak tertimbang bernilai negatif, dengan gap terbesar terjadi pada dimensi Empathy, yang disusul dengan gap lebih kecil, yaitu dimensi Reliability, Tangibles, Responsiveness, dan Assurance. Skor gap tersebut belum memperhitungkan tingkat kepentingan dimensi yang dirasakan pasien. Pada dimensi Empathy, terdapat beberapa item pernyataan dengan rincian skor gap berikut : 
Tabel 2. Skor Gap 5, Dimensi Empathy

\begin{tabular}{|c|c|c|c|}
\hline Faktor kepuasan & $\begin{array}{l}\text { Jasa yang } \\
\text { diharap- } \\
\text { kan pasien } \\
\text { (a) }\end{array}$ & $\begin{array}{l}\text { Jasa yang } \\
\text { dirasa- } \\
\text { kan pa- } \\
\text { sien (b) }\end{array}$ & $\begin{array}{l}\text { Gap } \\
5 \\
\text { (b-a) }\end{array}$ \\
\hline Empathy & 6,33 & 5,17 & $-1,16$ \\
\hline $\begin{array}{l}\text { 1. Rumah sakit akan } \\
\text { memberikan perhatian } \\
\text { khusus kepada para } \\
\text { pasiennya. }\end{array}$ & 6,20 & 5,18 & $-1,02$ \\
\hline $\begin{array}{l}\text { 2. Rumah sakit harus } \\
\text { memiliki jam la- } \\
\text { yanan yang nyaman } \\
\text { bagi semua pasien- } \\
\text { nya. }\end{array}$ & $\mathbf{6 , 5 5}$ & 4,94 & $-1,61$ \\
\hline $\begin{array}{l}\text { 3. Rumah sakit haruslah } \\
\text { memiliki karyawan } \\
\text { yang memberikan per- } \\
\text { hatian lebih mendalam } \\
\text { kepada para pasien. }\end{array}$ & 6,22 & 5,25 & $-0,97$ \\
\hline $\begin{array}{l}\text { 4. Rumah sakit haruslah } \\
\text { selalu mengutama- } \\
\text { kan kepentingan para } \\
\text { pasien. }\end{array}$ & 6,45 & 5,30 & $-1,15$ \\
\hline $\begin{array}{l}\text { 5. Karyawan rumah sakit } \\
\text { harus bisa memahami } \\
\text { kebutuhan spesifik } \\
\text { para pasiennya. }\end{array}$ & 6,23 & 5,17 & $-1,06$ \\
\hline
\end{tabular}

Dari tabel 2 ditemukan bahwa gap terbesar terjadi pada item pernyataan 'RSCC hrs memiliki jam layanan yang nyaman bagi semua pasiennya'. Selanjutnya diikuti dengan gap yang berturut-turut lebih kecil yaitu 'RSCC selalu mengutamakan kepentingan para pasien', 'Karyawan bisa memahami kebutuhan pasien', RSCC memberikan perhatian khusus kepada para pasien', dan 'RSCC memiliki karyawan yang memberikan perhatian lebih mendalam kepada pasien'. Hasil pengukuran skor tertimbang Gap 5 juga memperlihatkan skor negatif $(-0,21)$ yang terinci pada tabel berikut ini :

Tabel 3. Gap 5, Skor Tertimbang/Weighted

\begin{tabular}{|c|c|c|c|c|c|}
\hline $\begin{array}{l}\text { Dimensi } \\
\text { Kepuasan }\end{array}$ & $\begin{array}{l}\text { Jasa } \\
\text { yang } \\
\text { diharap- } \\
\text { kan } \\
\text { pasien } \\
\text { (a) }\end{array}$ & $\begin{array}{l}\text { Jasa } \\
\text { yang } \\
\text { dira- } \\
\text { sakan } \\
\text { pasien } \\
\text { (b) }\end{array}$ & $\begin{array}{l}\text { Bo- } \\
\text { bot } \\
\text { (c) }\end{array}$ & $\begin{array}{l}\text { Gap } 5 \\
\text { Un- } \\
\text { Weigh- } \\
\text { ted } \\
\text { (d) }\end{array}$ & $\begin{array}{l}\text { Gap } 5 \\
\text { Weighted } \\
\text { (c } \times \text { d) }\end{array}$ \\
\hline $\begin{array}{l}\text { Gap 5 } \\
\text { (Weigted } \\
\text { Score) }\end{array}$ & 6,33 & 5,29 & 0,20 & $-1,04$ & $-0,21$ \\
\hline 1. Tangibles & 6,16 & 5,13 & 0,21 & $-1,03$ & $-0,22$ \\
\hline $\begin{array}{l}\text { 2. Reliabi- } \\
\text { lity }\end{array}$ & 6,47 & 5,34 & 0,20 & $-1,13$ & $-0,23$ \\
\hline $\begin{array}{l}\text { 3. Respon- } \\
\text { siveness }\end{array}$ & 6,37 & 5,41 & 0,21 & $-0,95$ & $-0,20$ \\
\hline 4. Assurance & 6,32 & 5,38 & 0,20 & $-0,94$ & $-0,19$ \\
\hline 5. Empathy & 6,33 & 5,17 & 0,17 & $-1,16$ & $-0,20$ \\
\hline
\end{tabular}

Dari tabel 1 dan 3, dapat disimpulkan bahwa jasa yang dirasakan/dipersepsikan oleh pelanggan (service gap) lebih rendah daripada jasa yang diharapkan pelanggan, yang menimbulkan gap sangat besar sehingga kepuasan pasien masih rendah. Sementara itu, pada tabel 3 ditunjukkan bahwa tingkat kepentingan dimensi (bobot) menurut pelanggan berturut-turut adalah Resposiveness dan Tangibles, Reliability dan Assurance, terakhir Empathy, sehingga didapatkan hasil skor tertimbang Gap 5 berturut-turut dari gap terbesar adalah Reliability, selanjutnya Tangibles, Responsiveness dan Empathy, terakhir Assurance. Berdasarkan hasil penelitian tersebut maka peluang perbaikan kualitas pelayanan diprioritaskan sesuai tingkat kepentingan yang diusulkan oleh pelanggan.

\section{PEMBAHASAN}

Hasil penelitian menunjukkan bahwa secara keseluruhan kepuasan pasien di RSCC dinilai rendah, dengan adanya nilai yang negatif. Semakin negatif skor Servqual maka gap yang terjadi di mata pasien semakin serius. Penilaian kepuasan pelanggan secara keseluruhan digambarkan pada Gap 5, yang membandingkan gap antara jasa yang diharapkan dengan jasa yang dirasakan/dipersepsikan oleh pelanggan (service gap). Rendahnya kepuasan pelanggan tersebut terdapat pada dimensi Reliability, yaitu tentang kurangnya kemampuan RSCC untuk melaksanakan jasa yang dijanjikan kepada pasien dengan segera, akurat, baik, cermat, dan cepat. Hasil penelitian ini didapatkan dari skor tertimbang Gap 5, berdasarkan hasil pembobotan kepentingan menurut pelanggan. Pada pengukuran kepuasan pelanggan ini, yaitu Skor Tidak Tertimbang dan Skor Tertimbang, menghasilkan nilai negatif. Hal ini menunjukkan bahwa rumah sakit tidak memperhatikan hal-hal penting bagi pelanggan. Gap pada skor tertimbang menunjukkan peluang potensi untuk perbaikan persepsi kualitas jasa dengan mengubah kepentingan dan sumber daya dari segi pelayanan ke arah yang faktor lebih vital. Hasil perhitungan gap ini menunjukkan gap antara jasa yang dirasakan/ dipersepsikan oleh pelanggan lebih rendah daripada jasa yang diharapkan pasien. Jika harapan pelanggan lebih besar daripada kenyataan yang diterima, maka kualitas jasa yang diterima kurang memuaskan, dan timbullah ketidakpuasan pelanggan (Tjiptono, 2006).

Sementara itu, dimensi dengan nilai kepuasan terbaik, terdapat pada dimensi Assurance, tentang bagaimana 
karyawan memiliki pengetahuan memadai untuk menjawab pertanyaan-pertanyaan pasien. Seperti yang diungkapkan oleh Rubin (2005) bahwa untuk memperbaiki kepuasan pelanggan melalui pelayanan seharusnya fokus terhadap pelatihan para karyawan dalam upaya perbaikan keterampilan pribadi dan peningkatan pengetahuan saat melayani pasien. Maka selanjutnya perbaikan dimensi Empathy dilakukan dengan cara mengadakan pelatihan Service Excellent secara berkala untuk mengajarkan bagaimana menyampaikan pelayanan jasa yang baik dan benar sehingga pelanggan merasa nyaman dan diberi perhatian, dalam upaya memahami kebutuhan spesifik mereka. Pada suatu penelitian disebutkan bahwa walaupun kemungkinan besar relatifitas peringkat dari masing-masing dimensi akan berubah di masa yang akan datang, namun mereka yakin perhatian paling besar dari pelanggan adalah pada dimensi reliability, dan faktor paling sedikit menjadi perhatian dalam menilai kualitas pelayanan adalah dimensi tangibles.

\section{SIMPULAN}

Kepuasan pasien di RSCC secara keseluruhan, yang diukur melalui metoda Servqual, memberikan hasil bahwa kepuasan pelanggan masih rendah dengan adanya nilai yang negatif. Hal ini memerlukan perhatian dari manajemen untuk memperbaiki kepuasan pelanggan yang dimulai dari memperbaiki jam layanan supaya pasien menjadi lebih nyaman, dengan cara manajemen harus lebih dapat mengikat para dokter spesialis untuk lebih tertib terhadap jam prakteknya masing-masing, terutama untuk pasien dengan perjanjian. Juga perlu mengadakan Pelatihan Service Excellent secara berkala untuk meningkatkan rasa empati kepada pelanggan pada setiap pemberian pelayanan sehingga karyawan lebih bisa peka untuk memperhatikan dan memahami kebutuhan spesifik mereka. Pelatihan ini juga bertujuan untuk memberikan pelajaran sopan santun dan etika pelayanan, sehingga penyampaian jasa yang dijanjikan dapat terlaksana dengan segera, akurat, baik, cermat, dan cepat.

\section{DAFTAR PUSTAKA}

Bakar, C, Akgün, H.S, Al Assaf, A.F (2007), The Role of Expectations in Patient Assessments of Hospitalcare : An Example from A University Hospital Network, www.emeraldinsight. com/0952-6862.htm, Turkey.

Kaltcheva, V.D, Parasuraman, A (2009), PersonalityRelatedness and Resciprocity Framework For Analyzing Retailer-Customer Interactions, Journal of Business Research, 62, p. 601-608.

Parasuraman, A., Zeithmal, V.A, Berry, L.L. (1990), Delivering Quality Service: Balancing Customer Perceptions and Expectations, New York : The Free Press

Ramseook-Munhurrun, P, Lukea-Bhiwajee, S.D, Naidoo, P (2010), Service Quality In The Public Service, International Journal of Management and Marketing Reasearch, Vol.3, No. 1, University of Technology, Mauritis

Tjiptono, F (2006), Pemasaran Jasa, Malang : Bayumedia Publishing.

Urban, W (2009), Service Quality Gaps and Their Role In Service Enterprises Development, Baltic Journal On Sustainability, 15 (4) : 631645 , Poland. 